\title{
Social Learning, Self-Efficacy, and Subjective Norm in Exploring Betel Nut Chewing in Taxi Drivers
}

\section{in Taiwan}

Author list:

Tsui-Yun Yang, RN, PhD

Assistant Professor, School of Nursing, College of Medicine, Chang Gung University

Hung-Ru Lin, RN, PhD

Professor and Director, School of Nursing,

National Taipei University of Nursing and Health Sciences

\section{Correspondence to:}

Tsui-Yun Yang, RN, PhD

School of Nursing, College of Medicine, Chang Gung University

E-mail address: tyyang@mail.cgu.edu.tw

Fax: 886-3-2118800-5326

Telephone number: 886-3-2118800-5180

Physical address: No. 259, Wenhua 1st Rd., Guishan Township, Taoyuan County 333,

Taiwan

e-mail: tyyang@mail.cgu.edu.tw 


\section{ABSTRACT}

The betel nut chewing habit of taxi drivers has shown that can promote companionship, relaxation, and emotional stability at work. $19.3 \%$ of betel nut behaviors are instigated by an invitation among drivers to engage in the habit. The objective of this study was to explore the impact of social learning, subjective norm, and self-efficacy on betel nut chewing in taxi drivers in Taiwan. We conducted a crosssectional study on taxis' driver of betel nut behaviour and measured their evaluations of its consequences using a self-report questionnaire. Other variables include sociodemographic characteristics and chewing-related experience. The overall variance is $44.5 \%$ in socio-demographic variable, social learning, self-efficacy, and subjective norm. Results show that the variables of affected betel nut chewing behavior, driving years has the strongest influence, followed by learning about betel nut from the media, relatives, and friends, and education level, which positively affect betel nut chewing behavior. Findings indicated that education related to quitting betel nut chewing, significant others, and rules of the taxi fleet are adopted to design a plan for quitting betel chewing to reduce the positive expectations of taxi drivers for betel nut chewing and decrease their betel nut chewing behavior.

Keywords: social learning; self-efficacy; subjective norm; betel nut chewing; taxi driver

\section{Introduction}

Betel nut is the fourth most commonly abused substance after tobacco, alcohol, and caffeine [1]. A survey shows that approximately 0.6 billion people chew betel nut worldwide; betel nut chewers are mainly distributed in South Asia, Southeast Asia, and Pacific island countries[2]. In Taiwan, the number of people who chew betel nut has 
increased rapidly in the past six or seven years. A survey by the National Health Service of the Ministry of Health and Welfare showed that almost 2 million people chew betel nut, with males aged 40-49 accounting for $16.4 \%$ [3]. Betel nut chewing has become such a habit that betel nut is called "Taiwanese chewing gum" [4]. The high betel nut chewing rate in Asia is mainly related to traditional cultural customs, working environment, peer influence, stress adjustment, and other factors[1, 5, 6]. People who chew betel nut in Taiwan are primarily males with high (vocational) education and below, and are blue collar workers engaging in labor service[3, 7, 8, 9]. The characteristics of the betel nut chewing population are the same as those in other Asian countries $[5,6]$. However, the difference from other countries is that truck and taxi drivers in Taiwan have a higher betel nut chewing rate primarily because of working hours, lack of health knowledge, life experience, and poor interpersonal support [10, $11]$.

Betel nut in Taiwan is commonly characterized into three categories: (1) Lao-hwa quid, which is betel quid wrapping inflorescence, with added red ash and other spices; (2) betel quid, which is commonly known as Jingzi, coated with arecin, arecoline, polyphenols, and other compounds in the betel nut; and (3) stem quid, which is Piper betel coated with white ash and other spices wrapped around the betel quid [2, 12]. Arecoline excites the central nervous system, increasing the alertness of the chewers and maintaining a pleasant frame of mind, thereby inducing euphoria and relieving anxiety. Betel nut can also induce weak sympathetic nerves and cause people to have a psychological craving for chewing. Increased chewing quantity and frequency easily results in people developing a dependency on betel nut and even prevents them from having the urge to quit or stop chewing $[2,13,14]$. Betel nut has been shown to cause oral cancer [15]. In Taiwan, approximately 2,300 people die from oral cancer every year. 
Oral cancer is the fastest growing cancer that causes mortality among males [16]. Thus, government health authorities have begun to pay attention to the relationship between betel nut and health.

Social learning theory states that the learning of individual behavior is not controlled by a single factor of attitude, cognition, or environment but by interacting factors[17]. Relevant studies on the factors that affect betel nut chewers showed that the likelihood that one will engage in betel nut chewing increases when families or peers have a habit of chewing betel nut, thereby making betel nut easy to acquire in the living environment $[18,19]$. A survey of young people who chew betel nut showed that the habit is affected by their parents' chewing habits and pressure from classmates and friends[19]. They even regard betel nut chewing as a manifestation of masculinity[5, 20]. Such ideas increase the willingness of young people to chew betel nut. Studies on the betel nut chewing habit of taxi drivers in Taiwan have shown that betel nut is mainly used to boost the drivers' spirits to increase their working time. Drivers even chew up to 12 betel nuts every day[21]. Betel nut is an important support material during drivers' working hours and is also used to enhance interaction among peers. Moreover, betel nut chewing can relieve work stress[21]. Culture affects how people learn about betel nut chewing. Among Formosan aborigines[7, 22, 23, 24] and some people in Southeast Asian countries[18,25], betel nut is an indispensable item in various ceremonies and weddings, and it also symbolizes a vow of love or the blessings of elders[26], thereby increasing the chance of learning about betel nut chewing.

The attitude of significant others is an important factor that affects the use of substances. If significant others tend to be accepting of the habit, then the opportunities for material use will increase[27, 28]. A study on the smoking, drinking, or betel nut chewing habits of Taiwanese teenagers shows that their parents chew betel nut, and the 
father has the strongest influence[29]. Wang et al. (2004) pointed that 53.6\% of teenagers first learn to chew betel nut from their fathers[24]. Other studies have also shown that the betel nut chewing habit of fathers has the greatest influence on people after they have grown up[20]. Bandura (1986) indicated that the learning of individual behavior is supported by the social environment and affected by emotional stress, selfreflection, and self-evaluation[30]. A study on the betel nut chewing habit of employees in the transportation industry has shown that betel nut chewing can promote interpersonal relationships among colleagues. Findings indicate that $19.3 \%$ of betel nut behaviors are instigated by an invitation among drivers to engage in the habit[10]. Kuo and Lew-Ting (2008) interviewed taxi drivers and found that betel nut promotes companionship, relaxation, and emotional stability at work, even though it is an adaptive product that drivers have to chew before driving[21]. Even if the drivers know the negative health effects of betel nut, they have not considered giving up the habit.

The experience that individuals learn directly or indirectly from their lives will change into cognitive behavior. When individuals perform this behavior, they evaluate the feasibility of behaviors by using positive and negative perceptions[17]. Positive and negative outcomes expectancy predict the use and maintenance of different substances such as cigarettes, alcohol, and betel nut[31, 32, 33]. If chewers find that betel nut can enhance their positive expectations in their teams, then their chewing behaviors will be enhanced[5, 34]. Chuang et al. (2007) studied the positive expectations of the effects of betel nut and found that $56.4 \%$ of betel nut chewers believe that it can boost their spirits, and $32 \%$ of the chewers used it for stress release[10]. Li, Pentz, and Chou (2002) also found that depression is an important mediating factor in the use of tobacco, wine, and betel nut[35]. The study shows that substance users tend to regard negative mood or depression as a signal that they should increase their use of a substance. A highly 
negative mood or considerable depression corresponds to increased use frequency and amount of substance or drug. To extend driving time and increase their incomes, betel nut is the first choice of drivers because of its refreshing effect [10, 21]. Given the stressful working environment, traffic congestion, and economic pressures, betel nut and cigarette are key substances for relieving emotions and pressure[21, 36]. Studies on the use of cigarette and betel nut have shown a correlation between both substances, that is, smoking increases betel nut chewing ratio $[1,10,35]$. When chewers and their environment experience a positive emotional effect due to betel nut, then chewers' cognition and expectation for the effects of betel nut increase, thereby increasing their willingness to chew and behavior. The current paper aims to explore the influence of social learning, subjective norm, and self-efficacy on betel nut chewing in taxi drivers in Taiwan.

\section{Experimental Section}

\subsection{Study Design and Sample}

In this paper, taxi drivers who operate in the north, center, and south of Taiwan and who have been chewing one or more kinds of betel nut (including betel quid, Piper betel, or processed betel nut products) for at least six months were used as samples. Patients who suffer from head and neck cancers (including nasopharyngeal cancer, cancer of the nose and paranasal sinuses, oral cancer, oropharyngeal cancer, hypopharyngeal cancer, salivary gland cancer, and thyroid cancer) were excluded.

\subsection{Procedure}

Convenience sampling was adopted for data collection in car stations and taxi rest stations in north, central, and south Taiwan. The researchers introduced the purpose, procedure, and possible influence to the subjects, and informed them of their rights to 
quit the research at any time. The test was begun after the consent of the subjects was acquired. The questionnaires were filled by the subjects. The researcher provided explanations if the subjects experienced difficulty with the questionnaire. After the questionnaires were collected and the integration was checked, a gift was sent as a token of gratitude.

\subsection{Measurements}

\subsubsection{Socio-demographic variable}

The data include basic data (age, marriage status, family structure, and educational level), job attributes (place, driving years, daily mean working hours, and monthly mean income), substance use habits (cigarette, wine and betel nut usage habits; age when they first chewed; and situation when they first chewed betel nut), betel nut chewing behavior (daily spending on, whether they buy betel nut in a fixed location or not, the type and quantity of betel nut often chewed), and willingness to chew betel nut (current and future).

\subsubsection{Chewing betel nut outcome expectancy questionnaire}

The scale used in this paper is the chewing betel nut outcome expectancy developed by Ko [10]. The author's consent was obtained before the scale was used. The purpose of this scale is to test positive or negative self-efficacy on physical or emotion from betel nut chewing. The betel nut positive outcome expectation scale tests the positive personal image and perception of betel nut behavior, and the betel nut negative outcome expectation scale tests the negative perception of betel nut behavior; for example, the habit is hazardous to personal health and results in an unattractive appearance. The original scale has a total of 31 questionnaire items and uses mainly college students as subjects. In this paper, the subjects are adult taxi drivers. Thus, 
expert validity test should be conducted. After modification, the two subscales are the betel nut positive outcome expectation scale, with 14 items, and the betel nut negative outcome expectation scale, with 12 items. The score is 1 if the answer is yes and 0 if the answer is no; it is a dichotomous variable. If the score for betel nut positive outcome expectation is higher, then the frequency of betel nut chewing behavior is higher; if the score for betel nut negative outcome expectation is higher, then the frequency of betel nut chewing behavior is lower. Before the formal research, a reliability analysis of the research tool was conducted among 20 taxi drivers. The Cronbach's $\alpha$ of the total scale is .80 . The reliabilities are .77 and .71 for the betel nut positive outcome expectation scale and the betel nut negative outcome expectation scale, respectively.

\subsubsection{Social learning questionnaire}

This questionnaire aims to study if the occurrence and continuity of betel nut chewing in taxi drivers are subject to personal, environment, behavior, and other aspects of social learning and enhancement. The content contains two concepts: observation (behavior acquisition) and enhancement (behavior reward), and three parts, that is, observing relatives chewing betel nut, observing peers chewing betel nut, and observing betel nut chewing in the media. A total of six question items are given, and a six-point Likert scale is used, with scores in the range of 6-37. If the score is higher, then social learning has a higher impact on betel nut chewing. With regard to the reliability of this scale, the Cronbach's $\alpha$ is .75.

\subsubsection{Subjective norm questionnaire}

This questionnaire aims to study the attitude of significant others toward the use of betel nut under the social impact framework, which mainly includes social norms and information provided by significant others (parents, brothers and sisters, couples, 
friends), peers or working partners, and medical professionals (medical staff, health policies) given the expectation and willingness to chew betel nut to influence betel nut behavior. A total of six question items are given. A five-point Likert scale is used, with scores in the range of $0-30$. If the score is higher, then significant others are more opposed to the use of betel nut. With regard to the reliability of this scale, the Cronbach's $\alpha$ is .82 .

\subsection{Statistical Analysis}

The SPSS 20.0 for Windows was used for all data analyses in our study. Hypothesis test was conducted at $\alpha=.05$ significance level. For normal distribution, Kolmogorov-Smirmov test was adopted for fitness analysis. The raw scores of social learning, self-efficacy, subjective norm, and betel nut behavior and other variables did not have a normal distribution, and the measurement scales for the above variables were not the same. Therefore, the variance of all potential variables was set to 1.00 . The raw scores were changed to a standardized $\mathrm{z}$ value to achieve normal distribution. The mean value or standard deviation was used to analyze the basic data and the mean score of all question items of all scales. The $t$-tests and analysis of variance (ANOVA) were used to analyze the influence on betel nut chewing. We used multiple hierarchical regression to explain the total variance of taxis' behavior about betel nut chewing. A partial $\mathrm{F}$ test was then performed to determine the model that best fit in predicting outcome variables.

\section{Results}

\subsection{Analysis on socio-demographic variables of taxi drivers}

A total of 206 taxi drivers were investigated. They were mainly males, aged $48.70 \pm 9.57$, with high school education, married, and living with parents, couples, and children in nuclear families. Most of them work in north Taiwan (46.1\%), with driving 
years of $16.26 \pm 9.11$, daily driving hours of approximately $10.51 \pm 2.36$, and daily net incomes in the range of NT $\$ 10,000-70,000$ (US \$ 331.32-2319.32) (average of NT $\$ 33,060$ (US $\$ 1,095.34)$ ). A total of $82.6 \%$ of taxi drivers smoke, consuming approximately $1.17 \pm 0.77$ packs of cigarettes daily. Moreover, $65.3 \%$ of them started smoking when they were younger than 18 years old. In addition, $65.5 \%$ have a drinking habit, and $61.5 \%$ of them started drinking when they were younger than 18 years old. They first chewed betel nut at the age of approximately $20.38 \pm 6.40$, and they first encountered betel nut at 10 years old (11.4\%). Roommates (parents, brothers, and children) of $18.0 \%$ of the respondents have a habit of betel nut chewing. A total of $69.6 \%$ respondents obtained betel nut for the first time from friends. They spent NT $\$ 50-500$ (average of US \$ 5.49) on purchasing betel nut every day, and stem quid is used by $88.8 \%$ of the respondents. With regard to willingness to continue betel nut chewing, $30.6 \%$ of them will continue to chew betel nut, and $26.2 \%$ will continue to chew in the coming year (Table 1).

\subsection{Impact of social learning, self-efficacy, and subjective norm of taxi drivers on betel} nut behavior

To determine if betel nut chewing in taxi drivers is subject to social learning through media and relatives and friends, positive and negative outcome expectations for betel nut by himself, and the subjective norm of significant others with regard to betel nut. The result shows that the factors that indicate the significant impact of social learning on betel nut behavior include smoking and betel nut chewing habit of roommates $(\mathrm{t}=-1.986 ;-3.583)$, the number of cigarettes smoked per day $(\mathrm{t}=-4.228)$ and drinking habit $(t=-2.239)$, the age they chewed betel nut for the first time $(t=-$ 3.094), and driving years $(\mathrm{t}=13.462)$. For the impact of self-efficacy on betel nut behavior, the following has a significant effect on positive outcome expectation for 
betel nut: roommates with smoking, drinking, and betel nut chewing habits $(\mathrm{t}=-3.748$; $-2.390 ;-3.066)$, and smoking and drinking habits $(\mathrm{t}=-2.663 ;-3.225)$. The following has a significant effect on negative outcome expectation for betel nut: roommates with smoking, drinking, and betel nut chewing habits $(\mathrm{t}=4.212 ; 4.946 ; 3.34)$, smoking and drinking habits $(\mathrm{t}=2.788 ; 3.929)$, the number of cigarettes smoked daily $(\mathrm{t}=3.650)$, and the age they chewed betel nut for the first time $(\mathrm{t}=-6.401)$. The factors that have a significant impact of subjective norm on betel nut behavior are roommates with a betel nut chewing behavior $(\mathrm{t}=2.728)$, smoking habit $(\mathrm{t}=2.652)$, and the age they chewed betel nut for the first time $(\mathrm{t}=-3.479)$ (Table 2).

ANOVA showed that age, marriage status, educational level, and driving years significantly affect social learning, betel nut positive outcome expectation, norms, behavior, and willingness of significant others to accept the use of betel nut. For betel nut negative outcome expectation, only educational level has a significant impact. The above significant differences are compared by means of Scheffe post hoc test (Table 2). The result shows that roommates who have smoking and betel nut chewing habits, smoke more than one pack of cigarette, have a drinking habit, encountered betel nut before adulthood, have senior driving experience, and other factors have an increased chance of learning about betel nut use. The influencing factors of self-efficacy on betel nut behavior include an advanced age; being unmarried; lower education; having a roommate who engages in smoking, drinking, and betel nut chewing; engaging in smoking and drinking habits by themselves; and have higher positive outcome expectations for betel nut chewing. Betel nut chewing behaviors subject to social learning are observed among older taxi drivers who are unmarried or divorced with an educational level lower than high school; with roommates who smoke, drink, and chew betel nut; encountered betel nut, cigarette, and wine before adulthood; with long driving 
years; and work in south Taiwan. When they smoke more cigarettes, they are receptive to people who chew betel nut and have a higher positive cognition and expectation for betel nut; thus, they have a high probability of chewing betel nut at present and in the coming year. By contrast, taxi drivers with a high educational level who do not have roommates who smoke, drink, and chew betel nut, and who did not smoke or drink or encounter betel nut before adulthood have a higher negative outcome expectation for betel nut. The factors that cause subjective norm to affect betel nut chewing in drivers include a young age, high educational level, being married, encountering betel nut after adulthood, do not have a smoking habit, and having roommates who do not chew betel nut.

\subsection{Influence of demography variables on chewing willingness}

T-test and ANOVA are adopted to analyze the factors that affect the willingness of taxi drivers to chew betel nut at present and in the future. The significant factors are an age of more than 51 years old $(t=7.071)$, junior high school education $(t=15.897)$, and smoking more than one pack of cigarettes a day $(\mathrm{t}=15.897)$. The older taxi drivers with a low educational level and who smoke more estimate that they are more likely to chew betel nut at present and in the coming year.

\subsection{Predictive power of social learning, self-efficacy, and subjective norm on the betel} nut chewing behavior of taxi drivers

Significant variables in the bivariate test were selected for a regression model to examine the predictors of social learning, self-efficacy, and subjective norm on the betel nut chewing behavior of taxi drivers. We used hierarchical linear regression to choose the best set of variables to explain the total variance of the betel nut chewing behavior of taxi drivers. The mean daily expenditure on betel nut is used as a dependent variable 
for betel nut chewing. Independent variables are organized in four hierarchies by using stepwise regression. The first hierarchy includes demographic variables that are significantly different from betel nut chewing behavior, including age, marriage status, education level, substance use habits of roommates (smoking, drinking, betel nut chewing), their own substance use habits (smoking, quantity smoked, drinking), the age they chewed betel nut for the first time, sources of betel nut, driving years, working area, and ratio of betel nut chewing in the workplace. The second hierarchy includes learning about betel nut from the media and relatives and friends, and other social learning variables. Self-efficacy variables are included in the third hierarchy, with positive and negative outcome expectation. The fourth hierarchy includes the attitudes of significant others and subjective norm variables.

The result shows of the model total variance of demographic variables, social learning, subjective efficacy, and self-efficacy is $19.8 \%$. The predictive power of the demographic variables of taxi drivers in Model 1 is the best, with the individual explained variance reaching $10.7 \%(\mathrm{~F}=24.582, p<.0001)$. Adding the variable of learning about betel nut from the media and relatives and friends, and other social learning in Model 2, that produced a significant increase of $4.2 \%$ in the adjusted $\mathrm{R}^{2}$ that emerged (adjusted $\mathrm{R}^{2}=14.9 \%, \mathrm{~F}=10.115, p=0.002$ ). The next one is the subjective norm of significant others to betel nut chewing behavior in Model 4, with individual explained variance reaching $2.8 \%$ (adjusted $\mathrm{R}^{2}=15.7 \%, \mathrm{~F}=7.070, p=.008$ ). The last one is self-efficacy of positive and negative outcome expectation in Model 3, with individual explained variance reaching $2.0 \%$ (adjusted $\left.\mathrm{R}^{2}=19.8 \%, \mathrm{~F}=4.951, p=.027\right)$. In the global model of demographic variables, social learning, subjective efficacy, and self-efficacy, driving years among individual variables that positively influence betel nut chewing behavior $(\beta=.227, p=.001)$ is the most influential, followed by learning 
about betel nut from the media and relatives and friends $(\beta=.190, p=.008)$. The variables that negatively influence betel nut chewing behavior include education level ( $\beta=-.136, p=.047)$ and the age they chewed betel nut for the first time $(\beta=-.125, p$ $=.049)($ Table 3$)$.

The overall regression predictive power of betel nut chewing behavior shows that driving years, education level, learning about betel nut from the media and relatives and friends, and the age they first chewed betel nut have the strongest predictive power for betel nut chewing behavior.

\section{Discussion}

The taxi drivers in this study are mainly married males with a high school education and an average age of $48.70 \pm 9.57$. This result is similar to the demographic characteristics of other related studies on betel nut chewing[24, 37, 38]. Education affects personal health risk perception. If the educational level is lower, then betel nut chewing behavior is higher[7, 20,39]. This study also shows that the ratio of chewing betel nut among cases with elementary education is far higher than that of other educational levels. A study on the relationship between region and betel nut chewing shows higher betel nut usage in Eastern and Southern Taiwan[7, 22]. In this study, 46.1\% of taxi drivers work in the north, and the betel nut chewing behavior of taxi drivers in the south is higher than that of taxi drivers in the north. Yang and Lin (2017) interviewed taxi drivers who have successfully given up betel nut chewing[36]. The interview shows that the regulations of the fleet will affect the willingness to quit. Ninety percent of taxi drivers in north Taiwan belong to a special fleet. To enhance service quality and image, the fleet conducts strict convention management, and smoking, drinking, and betel nut chewing are prohibited during driving[39, 40]. 
Whether the rules of the fleet affect the chewing behavior of drivers or not will be further explored. This study reveals that long driving hours and senior driving experience increase betel nut chewing behavior. Betel nut causes euphoria and alertness in chewers[11, 41, 42]. Given their long driving hours and high work pressure, drivers chew betel nut to boost efficiency and increase their income $[25,38,36]$.

Betel nut chewing is also affected by the awareness of betel nut. This study reveals that the type of betel nut affects betel nut chewing in taxi drivers. The drivers prefer to chew betel quid wrapped in a leaf. Lao-hwa quid has a high pesticide content, which increases the possibility of developing liver cancer, thereby affecting the willingness of drivers to chew betel nut. Chou and Luo (2012) showed that Lao-hwa quid has a high safrole content; thus, extended periods of betel nut chewing will increase the risk of liver cancer [43]. Additives in the betel nut of Taiwan include Lao-hwa, betel leaf, lime, spices, and other substances [44]. These additives can enhance the taste of betel quid. To increase the purchasing rate of betel nut chewers, betel quid vendors formulate different recipes, thereby causing betel nut chewers to develop a difficult-to-control addiction $[25,36]$ and increasing their impulse to purchase betel nut.

A study on the effect of social learning on betel nut chewing behavior shows that betel nut learning of young population is subject to social media and relatives. This result is similar to other study findings. Betel nut chewing in teenagers is often due to their curiosity about betel nut $[22,24]$, the belief that betel nut chewing is a display of manliness [5], their inability to say no to their peers [39], and role identification [23]. If families adopt a neutral or accepting attitude toward these actions and the substance is easy to acquire, then the motivation of young people to continue chewing will increase $[7,45]$. The betel nut behavior of significant others will enhance the motivation to chew. Families and friends are the key [18]. The finding of this study is the same as 
the predictive result of media and relatives to betel nut behavior. This study also finds that if roommates chew betel nut, then people are more willing to chew and to continue their habit in the coming year. By contrast, if significant others are less accepting of the habit, then the betel nut chewing habit of people is reduced. Families' acceptance and disapproval of substance use are the most important determinants of abstinence $[36,46]$. The rules of parents in traditional Asian families have a binding effect on action learning [24]. The attitudes of significant others can be enhanced in the design of a betel nut quitting plan to increase the success of betel nut quitting.

In Taiwan, betel nut chewing is related to workplace culture. Through a qualitative interview, Yang and Lin (2017) found that cigarette and betel nut are tools for communicating feelings among drivers, and drivers invite one another to chew betel nut to avoid boredom while they are driving [36]. Moreover, the habit is a signifier among drivers. Driving experience has the strongest influence on betel nut behavior, and $69.9 \%$ of taxi drivers first chewed betel nut upon the invitation of their friends. They believe that betel nut has positive effects on their job, creating a sense of camaraderie, releasing working pressure, and stabilizing emotions. Moe et al. (2015) also found that betel nut is a social lubricant [5]. It can be used to enhance communication and the working atmosphere, and to release stress, and it does not produce withdrawal syndrome. The chewing behavior becomes acceptable to the public $[12,39]$, thereby enhancing the willingness to chew betel nut.

In substance behavior learning, positive effect expectation is the decisive factor in enhancing substance use [47]. This study shows that when two people smoke and drink, they have positive outcome expectations for betel nut use. Moreover, betel nut stimulates the central nervous system and produces pleasure, thereby increasing alertness $[11,38]$. A study on the smoking, drinking, betel nut chewing, and other 
substance use habits of adults in Taiwan showed that these habits often coexist [20, 38, 39]. The simultaneous use of betel nut and cigarette accounts for the highest percentage $[20,39]$. The mutual influence among cigarette, wine, and betel nut is also observed in Southeast Asian countries [6]. Taxi drivers work approximately 12 hours per day, facing a high level of stress from their working environment, income, and life while performing a repetitive task. They will rejuvenate themselves and improve their work efficiency by using substances such as cigarette and betel nut. This finding is the same as the results of a previous study $[11,38,45,48]$. A qualitative interview conducted by Yang and Lin (2017) showed that taxi drivers chew one or two betel nuts regularly, and they smoke to relax and eliminate boredom during irregular hours or while working at night[36].

When individuals can predict the outcome from the usage of those substances, the usage and maintenance of the substance can be effectively predicted $[35,49,50]$. This study shows that the positive and negative self-efficacies of betel nut have a predictive power for betel nut chewing. This finding is the same as the findings on the prediction of substance usage by self-efficacy [8, 25, 48]. If taxi drivers expect a positive effect from betel nut chewing, then their betel nut chewing rate will increase at present and in the coming year. Related studies show that betel nut chewing can induce feelings of pleasure, happiness, and rejuvenation in people faced with work. Betel nut has become a part of life to the point where people feel uncomfortable if they're not chewing betel nut $[1,5,11,36]$. Lee et al. (2016) also found that the physiological and psychological desire for betel nut is an important factor in determining betel nut chewing [48]. Education is significantly related to expected negative effects on substance behavior. Chang et al. (2009) found that social influence and rejection of self-efficacy directly affect the willingness to chew betel nut, and expected positive and negative effects can 
indirectly result in people giving up betel nut chewing through the refusal of selfefficacy [29]. Through studies on abstinence, Black, Tran, Goldsmith, Thompson, Smith, and Welge (2012) found that reducing alcohol positive expectancy and increasing refusal efficacy can effectively enhance the abstinence effect [51]. Chen et al. (2014) also found that the initiative of negative outcome expectations of betel nut on people's health can reduce betel nut chewing [1]. Therefore, betel nut chewing can be reduced by enhancing cognition of the negative health effects of betel nut. Betel nut chewing in taxi drivers is subject to personal, family, working environment, and learning norms, as well as the expected positive and negative effects of betel nut. Betel nut is proven to influence health. In future betel nut prevention and intervention plans, positive outcome expectations for the effects of betel nut should be reduced, and the perceptions of significant others toward betel nut use should be included to enable people to effectively give up betel nut chewing.

\section{Conclusions}

Betel nut is used by taxi drivers to relieve work stress. Under such culture, the probability of betel nut chewing is virtually increased. In considering how the influence of betel nut chewing on health can be prevented and determining how one can successfully quit betel nut chewing, driving years is an important predictive factor that influences betel nut behavior. Fleets and medical teams should be integrated in betel nut withdrawal plans. The health of taxi drivers is maintained through education on norms and health beliefs in fleets and through the support of family members or significant others.

\section{Limitation}

In this study, $90 \%$ of taxi drivers work with special fleets. Fleets set stipulations 
to maintain the image and quality of their service. Thus, chewing betel nut during work is prohibited. Even if taxi drivers chew betel nut, the reliability of the questionnaire will be influenced because the respondents may be worried about violating fleet rules. The study areas were Northern, Central, and Southern Taiwan. However, a taxi is a constantly moving vehicle. Cases were mainly collected at taxi rest stations or stops. As a result, the usage of taxis in the north is higher, and more cases were collected in the north than in other areas, thereby further influencing the findings. Future research should be designed to combine taxi associations and members of regional associations to compare the usage of betel nut by region.

\section{Acknowledgements}

Ethical approval: In the original plan of this study, taxi drivers in Northern Taiwan were used as the subjects. The cases were collected after approval by the Research Committees at a certain teaching hospital in northern Taiwan in 2013 (IRB No.1014033B). The number of investigated subjects was inadequate. Thus, research areas in Central and Southern Taiwan were added. The research was approved by the Research Committees at a certain teaching hospital in northern Taiwan in 2014 (IRB No.1024002C). The authors gratefully acknowledge the principals, taxi drivers who assisted with the dissemination and collection of the questionnaires.

\section{Author Contributions}

Study design: Y-TY, L-HR; data collection and analysis: Y-TY; and manuscript preparation: Y-TY, L-HR.

\section{Conflict of interest}

The authors declare no competing interests. 


\section{References:}

1.Chen, F.L.; Chen, P.; Tung, T.H.; Huang. Y.C.; Tsai, M.C: The role of betel-quid chewing in smoking cessation among workers in Taiwan. BMC Public Health. 2014, 14, 755, dio: 10.1186/1471-2458-14-755.

2.Gupta, P.C.; Warnakulasuriya, S. Global epidemiology of areca nut usage. Addiction Biology. 2002, 7(1), 77-83, dio:10.1080/13556210020091437

3.National Health Interview Survey (NHIS). R.O.C. Taiwan. Bureau of Health Promotion (BHP), Department of Health, the Executive Yuan. 2012. Available online: http://www.mohw.gov.tw/fp-3159-24502-1.html (in Chinese) (accessed on 18 October 2016).

4.Tung, T.H.; Chiu, Y.H.; Chen, L.S.; Wu, H.M.; Boucher, B.J.; Chen, T.H. A population based study of the association between areca nut chewing and type 2 diabetes mellitus in men. (Keelung Community-based Integrated Screening programme No. 2). Diabetologia, 2004, 47(10), 1776- 1781, doi:10.1007/s00125004-1532-2.

5.Moe, T.; Boonmongkon, P.; Lin, C.F.; Guadamuz, T.E. Yauk gyar mann yin (Be a Man!): Masculinity and betel quid chewing among men in Mandalay, Myanmar. Culture, Health Sexuait, 2015, 18(2), 129-142, doi:10.1080/13691058.2015.1055305.

6.Petti, S.; Masood, M.; Scully, C. The magnitude of tobacco smoking-betel quid chewing-alcohol drinking interaction effect on oral cancer in south-east Asia. A 
meta-analysis of observational studies. PLoS ONE. 2013, 8(11), e78999, doi:10.1371/journal.pone.0078999.t002.

7.Che, C.M.; Kuo, L.C.; Lin, L.; Lee, J.L. Health risk perception and betel chewing behavior -The evidence from Taiwan. Addictive Behaviors. 2013, 38(11), 2714 2717.

8.Chang C.H.; Ko, H.C.; Wu, J.Y. Cheng C.P. Social cognitive determinants of betel quid chewing among college students in southern Taiwan: A revised AttitudesSocial Influence-Efficacy Model. Addictive Behaviors. 2007, 32(10), 2345-2350, doi:10.1016/j.addbeh.2007.02.001.

9.Wen, C.P.; Cheng, C.W.; Cheng, T.Y.; Tsai, M.K.; Chiang, P.O.H.; Tsai, S.P.; Chan, H.T.; Chang, Y.C.; Chang, H.Y.I. Trends in betel quid chewing behavior in Taiwan-exploring the relationship between betel quid chewing and smoking. Taiwan Journal of Public Health. 2009, 28(5), 407-419. (in Chinese)

10.Chuang, C.Y.; Chang, C.H.; Chang, C.C. The workplace relevant factors of betel quid chewing among transportation workers in Central Taiwan. Taiwan Journal Public Health. 2007, 26(5), 433-442. (in Chinese)

11.Keng, S.H.; Sheu, S.J. The effect of stimulants and their combined use with cigarettes on mortality: the case of betel quid. The European Journal of Health Economics. 2013, 14(4), 677-695, dio:10.1007/s10198-012-0415-6.

12.Huang, H.L.; Lee, C.H.; Yen, Y.Y.; Chen, T.; Chen, F.L.; Ho, P.S.; Lai, T.C.; Tsai, W.L.; Hsu, C.C. School-level contextual factors associated with betel quid chewing among schoolchildren in Taiwan. Community Dent Oral Epidemiology. 2009, 37(1), 58-67, doi:10.1111/j.1600-0528.2008.00442.x. 
13.Winstock, A.; Trivedy, C.R.; Warnakulasuriya, K.A.A.S.; et al. A dependency syndrome related to areca nut use: some medical and psychological aspects among areca nut users in the Gujarat community in the UK. Addiction. Biology. 2000, 5(2), 173-179, doi: 10.1080/13556210050003766.

14.Winstock, A. Areca nut-abuse liability, dependence, and public health. Addiction. Biolology. 2002, 7(1), 133-138, doi:10.1080/13556210120091509.

15.International Agency for Research on Cancer. Betel quid and areca-nut chewing. IARC Monographs. 1985, 85, 45-278.

16.BHP: National Health Interview Survey (NHIS). R.O.C. Taiwan. Bureau of Health Promotion (BHP), Department of Health, the Executive Yuan. 2015. Available online: http://www.mohw.gov.tw/cp-16-33598-1.html (in Chinese) (accessed on 18 September 2016).

17.Bandura, A. Self-efficacy: Toward a unifying theory of behavioral Change.

Psychologist Review. 1977; 84:191-215.

18.Dorji, N.; Pacheun, O.; Boonshuyar, C. Chewing of betel quid: why do health careproviders in Thimphu, Bhutan, do it? Journal of the Medical Association of Thailand. 2012, Suppl 6, 147-153.

19.Wang, S.C.; Tsai, C.C.; Huang, S.T.; Hong, Y.J. Betel nut chewing and related factors in adolescent students in Taiwan. Public Health. 2003, 117(5), 339-345, doi:10.1016/S0033-3506(03)00082-9.

20.Yap, S.F.; Ho, P.S.; Kuo, H.C.; Yang, Y.H. Comparing factors affecting 
commencement and cessation of betel quid chewing behavior in Taiwanese adults. Bio Med Central Public Health. 2008, 8: 199, doi:10.1186/1471-2458-8199.

21.Kuo, S.C.; Lew-Ting, C.Y. The Health Lifestyles of Areca quid-chewing Taxi Drivers-An Exploratory Study from the Viewpoint of Social Context. Taiwan Journal of Public Health. 2008, 27(1), 67-80. (in Chenese)

22.Chen, H.Y.; Waigandt, A.C. Betel nut chewing behavior among adolescents in eastern Taiwan: a cluster analysis. Journal of Drug Education. 2009, 39(1), 73-93.

23.Lin, C.C.; Tamí-Maury I.; Ma, W.F.; Lam, C.; Tsai, M.H.; Lin, M.T.; Li, C.I.; Liu, C.S.; Li, T.C.; Chiu, C.F.; Lu, I.Y.; Gritz, E.R. Social and cultural context of betel quid consumption in Taiwan and implications for prevention and cessation interventions. Substance Use and Misuse. 2017, 52(5), 646-655, doi:10.1080/10826084.

24.Wang, S.C.; Tasi, C.C.; Huang, S.U.; Hong, Y.J. Betel nut chewing: the prevalence and the intergenerational effect of parental behavior on adolescent students. Journal of Adolescent Health. 2004, 34(3), 244-249, doi:10.1016/j.jadohealth.2003.07.008.

25.Little, M.A.; Pokhrel, P.; Murphy, K.L.; Kawamoto, C.T.; Suguitan, G.S.; Herzog, T.A. Intention to quit betel quid: A comparison of betel quid chewers and cigarette smokers. Oral Health Dent Management. 2014, 13(2), 512-518.

26.Ma, W.F.; Li, C.I.; Gritz, E.R.; Tamí-Maury, I.; Lam, C.; Lin, C.C. A symbol of connectedness between the self and the tribal home: Betel quid in the lives of indigenous Taiwanese. The Journal of Nursing. 2017, 64(3), 65-73. (in Chinese) 
27.Jenkins, J.E.; Zunguze, T. The relationship of family structure to adolescent drug use, peer affiliation, and perception of peer acceptance of drug use. Adolescence. 1998, 33(132), 811-822.

28.Epstein, J.; William, C.; Bovtvin, G.J. How universal are school influences to drink and problem for alcohol use? A test comparing urban African American and Caribbean American adolescents. Addictive Behaviors. 2002, 27, 75-86.

29.Chang, C.S. A Study on the relationship among behavior of substance use, social influence and risk perception among Junior High School students. National Taiwan Normal University (master's thesis). 2008. Available online: http://handle.ncl.edu.tw/11296/ndltd/59619597869330369990 (in Chinese) (accessed on 1 May 2016).

30.Bandura, A. Social foundation of thought and action: A social cognitive theory, 1st ed.; Englewood Cliffs, NJ:Prentice-Hall, 1986. ISBN-10: 013815614X.

31.Connor, J.P.; Young, R.M.; Williams, R.J.; Ricciardelli, L.A. Drinking restraint versus alcohol expectancies: Which is the better indicator of alcohol problems? Journal of Studies on Alcohol. 2000, 61(2), 352-359, doi:10.15288/jsa.2000.61.352.

32.Li, S.M.,;Yu, R.L.; Hu, H.C.; Huang, J.S. Areca quid chewing by Taiwanese adolescents: application of Attitude Social Influence Self-efficacy (ASE) model. Addiction. 2003, 98(12), 1723-1729, doi:10.1111/j.1360-0443.2003.00543.x.

33.Lu, H.H. The Investigation of Prevalence and Risk Factors in Betel Quids Chewing and Dependence in Aborigines of Ping-Tong County. Kaohsiung Medical University, Taiwan (master's thesis). 2013. Available online: 
http://handle.ncl.edu.tw/11296/ndltd/22840630128335101220 (in Chinese) (accessed on 1 May 2016).

34.Chen, H.C.; Ko, H.C.; Lee, K.H.; Lin, M.P. Depression, cognitive determinants, and social influence in explaining betel nut chewing among college students in southern Taiwan. Formosa Journal of Mental Health. 2010, 23(4), 587-612. (in Chinese)

35.Li, C.; Pentz, M.A.; Chou, C.P. Parental substance use as a modifier of adolescent substance use risk. Addiction. 2002, 97(12), 1537-1550, doi:10.1046/j.13600443.2002.00238.x.

36.Yang, Y.T.; Lin, H.R. Taking actions to quit chewing betel nuts and starting a new life: taxi drivers' successful experiences of quitting betel nut chewing. Journal of Clinical Nursing. 2017, 26(7-8), 1031-1041, doi:10.1111/jocn.13599.

37.Jang, S.A.; Rimal, R.N.; Cho, N. Normative influences and alcohol consumption: The role of drinking refusal self-efficacy. Health Communication. 2013, 28(5), 443-451, doi:10.1080/10410236.2012.691455.

38.Lai, C.S.; Shieh, T.Y.; Yang, Y.H.; Chong, M.Y.; Hung, H.C.; Tsai, C.C. Factors associated with quitting areca (betel) quid chewing. Community Dentistry Oral Epidemiology. 2006, 34(6), 467-474, doi:10.1111/j.1600-0528.2006.00305.x.

39.Wu, C.L. A Study on the Relationship between Service Quality, Customer Satisfaction and Customer Loyalty of Taxi Industry in Taipei Area. National Chiao Tung University, Taiwan (master's thesis). 2006. Available online: http://hdl.handle.net/11536/81761 (in Chinese) (accessed on 16 May 2016). 
40.Wang, L.C. Exploring a Firm's Improvisation Process of business model transformation - A Case of Taiwan Taxi. National Taiwan University, Taiwan(master's thesis). 2006. Available online:

http://handle.ncl.edu.tw/11296/ndltd/79123869815478372645 (in Chinese) (accessed on 1 May 2016).

41.Wu, D.M.; Chu, N.F.; Lin, Y.S.; Lai, H.R. Aggregation of adverse behaviors and its affecting factors among young military conscripts in Taiwan. Addictive Behaviors. 2007, 32(6), 1302-1308, doi:

42.Chu, N.F. Effects of betel quid chewing on the central and autonomic nervous systems. Journal Biomedical Science. 2001, 8, 229-236.

43.Chou, Y.T.; Luo, C.W. Concomitant oral squamous cell carcinoma and Hepatic cell carcinoma- A case report. Taiwan Journal Oral Macillofac Surg. 2012, 23, 205 212. (in Chinese)

44.Wen, C.P.; Tsai, S.P.; Cheng, T.Y.; Chen, C.J.; Levy, D.T.; Yang, H.J.; Eriksen, M.P. Uncovering the relation between betel quid chewing and cigarette smoking in Taiwan. Tobacco Control. 2005, Suppl 1: i16-22, doi:10.1136/tc.2004.008003.

45.Htin, K.; Howteeraku, N.; Suwannapong, N.; Tipayamongkholgull, M. Smoking, alcohol consumption and betel-quid chewing among young adult Myanmar laborers in Thailand. The Southeast Asian Journal of Tropical Medicine and Public Health. 2014, 45(4), 926-939.

46.Mills, A.M.; Rhodes, K.V.; Follansbee, C.W.; Shofer, F.S.; Prusakowski, M.; Bernstein, S.L. Effect of household children on adult ED smokers' motivation to quit. American Journal of Emergency Medicine. 2008, 26(7), 757-762, 
doi:10.1016/j.ajem.2007.10.024.

47.Hayaki, J.; Herman, D.S.; Hagerty, C.E.; de Dios, M.A.; Anderson, B.J.; Stein, M.D. Expectancies and self-efficacy mediate the effects of impulsivity on marijuana use outcomes: An application of the acquired preparedness model. Addictive Behaviors. 2011, 36(4), 389-396, doi:10.1016/j.addbeh.2010.12.018.

48.Lee, C.Y.; Lu, B.; Shieh, T.Y.; Chang, Y.Y. Patterns of betel quid, cigarette, and alcohol use, and their correlates with betel quid cessation in a male inmate population. Substance Use and Misuse. 2016, 51(4), 471-478, doi:0.3109/10826084.2015.

49.Kavanagh, D.J.; Sitharthan, T.; Sayer, G. Prediction of results from correspondence treatment for controlled drinking. Addiction. 1996, 91(10), 1539-1545.

50.Leigh, B.C.; Stacy, B.W. Alcohol outcome expectancies: scale construction and predictive utility in high order confirmatory model. Psychological Assessment. 1993, 5(2), 216-229, doi: 10.1037/1040-3590.5.2.216.

51.Black, J.J.; Tran, G.Q.; Goldsmith, A.A.; Thompson, R.D.; Smith, J.P.; Welge, J.A. Alcohol expectancies and social self-efficacy as mediators of differential intervention outcomes for college hazardous drinkers with social anxiety. Addictive Behaviors. 2012, 37(3), 248-255, doi:10.1016/j.addbeh.2011.10.004. 
Table 1. Soci-demographic variables of taxi drivers

\begin{tabular}{|c|c|c|c|c|}
\hline Variable & & Mean $\left(\mathrm{SD}^{\mathrm{a}}\right)$ & percentage & $(\%)$ \\
\hline \multicolumn{5}{|l|}{ Basic date } \\
\hline Age & & $48.70 \pm 9.57$ & & \\
\hline \multicolumn{5}{|l|}{ marriage status } \\
\hline unmarried & 48 & & 23.3 & \\
\hline married & 128 & & 62.1 & \\
\hline devoiced & 30 & & 14.6 & \\
\hline \multicolumn{5}{|l|}{ family structure } \\
\hline extended family $y^{b}$ & 43 & & 20.9 & \\
\hline nuclear familyc & 112 & & 54.3 & \\
\hline one-parent family & 16 & & 7.8 & \\
\hline live alone & 35 & & 17.0 & \\
\hline \multicolumn{5}{|l|}{ education level } \\
\hline elementary school & 36 & & 17.5 & \\
\hline junior high school & 75 & & 36.4 & \\
\hline senior high school & 95 & & 46.1 & \\
\hline \multirow{2}{*}{\multicolumn{5}{|c|}{ Job attributes }} \\
\hline \multicolumn{3}{|l|}{$\overline{\text { work area }}$} & & \\
\hline north & 95 & & 46.1 & \\
\hline central & 45 & & 21.8 & \\
\hline south & 66 & & 32.1 & \\
\hline driving years & & $16.26 \pm 9.11$ & & \\
\hline daily mean driving hours & & $10.51 \pm 2.36$ & & \\
\hline monthly mean income (US dollars) & & NT $\$ 33,060 \pm 12,366$ & & \\
\hline & & (US \$ 1095.34 $₫ 409.71)$ & & \\
\hline \multirow{2}{*}{\multicolumn{5}{|c|}{ substance use habits }} \\
\hline & & & & smoking \\
\hline no & 36 & & 17.4 & \\
\hline yes & 170 & & 82.6 & \\
\hline \multicolumn{5}{|l|}{ drinking } \\
\hline no & 71 & & 34.5 & \\
\hline yes & 135 & & 65.5 & \\
\hline \multicolumn{5}{|l|}{ betel nut chewing } \\
\hline \multirow{2}{*}{\multicolumn{5}{|c|}{ first chewed situation }} \\
\hline & & & & \\
\hline by himself & 50 & & 24.3 & \\
\hline family & 12 & & 5.8 & \\
\hline friends & 144 & & 69.9 & \\
\hline \multicolumn{5}{|l|}{ betel nut chewing behavior } \\
\hline daily spending on (US) & & $5.50 \pm 4.70$ & & \\
\hline place of purchase & & & 47.6 & \\
\hline fixed location & 98 & & 52.4 & \\
\hline no & 108 & & & \\
\hline chewing type & & & 3.9 & \\
\hline betel quid & 8 & & 7.3 & \\
\hline Jingzi & 15 & & 88.8 & \\
\hline tem quid & 183 & & & \\
\hline
\end{tabular}

${ }^{\mathrm{a}} \mathrm{SD}=$ standard deviation; ${ }^{\mathrm{b}}$ living with grandparents, spouse and children; ${ }^{\mathrm{c}}$ living with spouse and children only 
Table 2. Impact of social learning, self-efficacy, and subjective norm of taxi drivers on betel nut behavior

\begin{tabular}{|c|c|c|c|c|c|c|c|c|c|c|c|c|}
\hline \multirow{2}{*}{$\begin{array}{l}\text { Variables } \\
\text { Instruments }\end{array}$} & \multicolumn{3}{|c|}{$\begin{array}{l}\text { Social learning } \\
\text { Friends and media learning }\end{array}$} & \multicolumn{6}{|c|}{ Self-efficacy } & \multicolumn{3}{|c|}{$\begin{array}{c}\text { Subject norm } \\
\text { Significant others attitude }\end{array}$} \\
\hline & $\begin{array}{l}\text { mean } \\
(S D)\end{array}$ & $t / F^{\mathrm{a}}$ & post hoc & $\begin{array}{l}\text { mean } \\
(\mathrm{SD})\end{array}$ & $\mathrm{t} / \mathrm{F}^{\mathrm{a}}$ & post hoc & $\begin{array}{l}\text { mean } \\
(\mathrm{SD})\end{array}$ & $t / F^{\mathrm{a}}$ & post hoc & $\begin{array}{l}\text { mean } \\
(\mathrm{SD})\end{array}$ & $t / F^{\mathrm{a}}$ & post hoc \\
\hline \multicolumn{13}{|l|}{ Demographic variable } \\
\hline Age & & $9.626^{* *}$ & & & $4.895^{* *}$ & & & 2.646 & & & $3.970^{*}$ & \\
\hline$(1) \leqq 40$ & $15.83 \pm 2.43$ & & $(3)>(1)$ & $22.65 \pm 3.30$ & & $(3)>(1)^{*}$ & $20.30 \pm 3.15$ & & & $19.90 \pm 6.30$ & & $(1)>(3)$ \\
\hline (2) $41-50$ & $17.89 \pm 5.12$ & & $(3)>(2)$ & $23.14 \pm 3.68$ & & $(3)>(2)^{*}$ & $19.47 \pm 2.96$ & & & $\begin{array}{l}18.76 \pm 6.34 \\
1636+839\end{array}$ & & \\
\hline$(3) \geqq 51$ & $19.78 \pm 5.26$ & & & $23.58 \pm 3.48$ & & & $19.37 \pm 3.38$ & & & & & \\
\hline Marriage status & & $3.989^{*}$ & & & $3.337^{*}$ & & & 1.361 & & & $5.121^{* *}$ & $(2)>(1)$ \\
\hline (1)unmarried & $19.92 \pm 4.98$ & & $(1)>(2)$ & $24.54 \pm 2.57$ & & $(1)>(3)^{*}$ & $19.27 \pm 3.26$ & & & $15.90 \pm 6.70$ & & \\
\hline (2)married & $17.58 \pm 5.08$ & & & $23.46 \pm 3.62$ & & & $19.62 \pm 3.67$ & & & $19.27 \pm 7.37$ & & \\
\hline (3) devoiced & $18.47 \pm 3.94$ & & & $22.53 \pm 3.88$ & & & $18.50 \pm 3.56$ & & & & & \\
\hline Education level & & $12.240^{* *}$ & & & $4.527^{* *}$ & & & $16.440^{* *}$ & & & $8.099^{* *}$ & \\
\hline (1)elementary school & $22.14 \pm 4.81$ & & $(1)>(3)$ & $25.36 \pm 2.29$ & & $(1)>(3)$ & $17.08 \pm 3.93$ & & $(1)<(2)$ & $14.00 \pm 7.45$ & & $(3)>(1)$ \\
\hline (2)junior high school & $18.39 \pm 4.53$ & & $(1)>(4)$ & $23.52 \pm 3.37$ & & $(1)>(4)$ & $18.56 \pm 2.82$ & & $(1)<(3)$ & $16.97 \pm 6.06$ & & $(4)>(1)$ \\
\hline (3)senior high school & $16.61 \pm 4.58$ & & $(2)>(3)$ & $23.05 \pm 3.54$ & & $(2)>(3)$ & $20.77 \pm 3.01$ & & $(1)<(4)$ & $20.40 \pm 7.40$ & & $(3)>(2)$ \\
\hline (4)university & $16.90 \pm 4.75$ & & $(2)>(4)$ & $22.55 \pm 3.69$ & & $(2)>(4)$ & $21.30 \pm 2.05$ & & $(2)<(3)$ & $20.20 \pm 7.12$ & & \\
\hline \multicolumn{13}{|l|}{ substance use habits of } \\
\hline \multicolumn{13}{|l|}{ roommates } \\
\hline smoking & & $-1.986^{*}$ & & & $-3.478^{* *}$ & & & $4.212^{* *}$ & & & 1.608 & \\
\hline No & $17.78 \pm 4.84$ & & & $23.00 \pm 3.54$ & & & $20.04 \pm 2.86$ & & & $15.58 \pm 7.45$ & & \\
\hline Yes & $19.24 \pm 5.16$ & & & $24.76 \pm 3.07$ & & & $18.00 \pm 3.94$ & & & $16.84 \pm 7.00$ & & \\
\hline drinking & & -.666 & & & $-2.390^{* *}$ & & & $4.946^{* *}$ & & & .768 & \\
\hline No & $18.11 \pm 4.95$ & & & $23.23 \pm 3.58$ & & & $20.04 \pm 2.95$ & & & $18.25 \pm 7.51$ & & \\
\hline Yes & $18.64 \pm 5011$ & & & $24.53 \pm 3.02$ & & & $17.55 \pm 3.82$ & & & $17.36 \pm 6.84$ & & \\
\hline betel nut & & $-3.583^{* *}$ & & & $-3.066^{* *}$ & & & $3.347^{* *}$ & & & $2.728^{* *}$ & \\
\hline No & $17.69 \pm 4.76$ & & & $23.24 \pm 3.45$ & & & $19.73 \pm 3.16$ & & & $18.66 \pm 7.19$ & & \\
\hline Yes & $20.84 \pm 5.22$ & & & $25.14 \pm 3.24$ & & & $17.73 \pm 3.88$ & & & $15.08 \pm 7.35$ & & \\
\hline \multicolumn{13}{|l|}{ own substance use habit } \\
\hline smoking & & -1.331 & & & $-2.663^{* *}$ & & & $2.788^{* *}$ & & & $2.652^{* *}$ & \\
\hline No & $17.25 \pm 3.96$ & & & $22.19 \pm 4.09$ & & & $20.78 \pm 2.22$ & & & $20.92 \pm 7.10$ & & \\
\hline
\end{tabular}




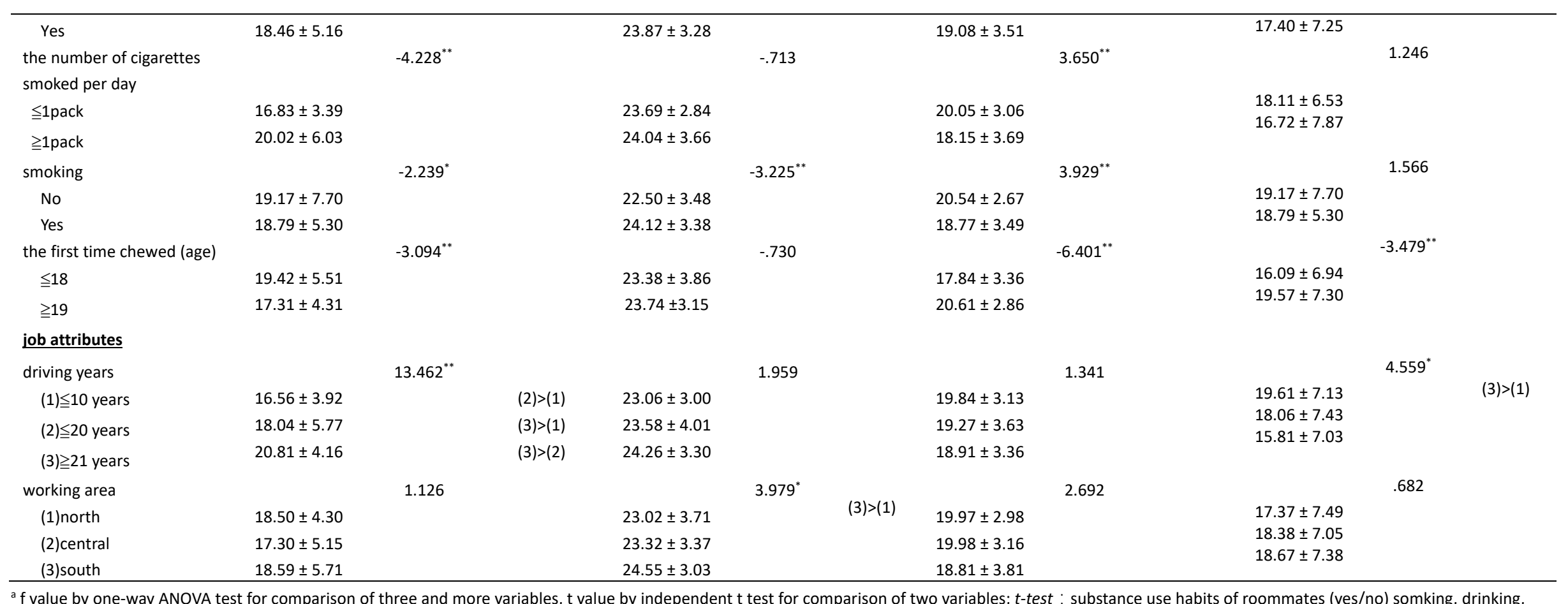

betel nut chewing; own substance use (yes/no)-smoking, quantity smoked ; smoking the first chewed (age); ANOVA : Demographic variable -age, marriage status, education level; job attributes - driving years, area

${ }^{\mathrm{b}}$ living with grandparents, parents, wife and child

${ }^{*} p<.05 ;{ }^{* *} p<.01$ 
Table 3. Predictive power of social learning, self-efficacy, and subjective norm on the betel nut chewing behavior of taxi drivers

\begin{tabular}{|c|c|c|c|c|c|c|c|}
\hline \multirow[b]{2}{*}{ model } & \multirow[b]{2}{*}{$\begin{array}{l}\text { Dependent } \\
\text { Variable }\end{array}$} & \multirow[b]{2}{*}{$\mathrm{R}^{2}$} & \multirow[b]{2}{*}{ Beta } & \multirow[b]{2}{*}{$\mathrm{T}$} & \multirow[b]{2}{*}{$p$} & \multicolumn{2}{|c|}{ Collinearity analyses } \\
\hline & & & & & & Tolerance & VIP \\
\hline 1 & driving years & .107 & .327 & 4.985 & $.00^{* *}$ & 1.000 & 1.000 \\
\hline \multirow[t]{2}{*}{2} & driving years & .149 & .291 & 4.432 & $.00^{* *}$ & .969 & 1.032 \\
\hline & education level & & -.209 & -3.180 & .002 & .969 & 1.032 \\
\hline \multirow[t]{3}{*}{3} & driving years & .157 & .277 & 4.239 & $.00^{* *}$ & .960 & 1.041 \\
\hline & education level & & -.198 & -3.032 & .003 & .964 & 1.038 \\
\hline & age of first chewing betel nut & & -.144 & -2.225 & .027 & .982 & 1.019 \\
\hline \multirow[t]{4}{*}{4} & driving years & .198 & .227 & 3.395 & .001 & .886 & 1.128 \\
\hline & education level & & -136 & -1.997 & .047 & .854 & 1.171 \\
\hline & the first chewed & & -125 & -1.950 & .049 & .970 & 1.031 \\
\hline & $\begin{array}{c}\text { learning about betel nut from } \\
\text { the media and relatives }\end{array}$ & & .190 & 2.659 & .008 & .778 & 1.286 \\
\hline
\end{tabular}

model one- Demographic variable; model two-Social learning (learning about betel nut from the media and relatives);

model three-Subjective norm (attitudes of significant others); model four-self-efficacy (positive outcome expectancy, negative outcome expectancy) 